\title{
Safety Profile and Patient Satisfaction of the Routine use of Propofol in Gastrointestinal Endoscopy. Gurung $\mathrm{RB}^{1}$, Purbe $\mathrm{B}^{1}$, Malla $\mathrm{B}^{2}$, Dhungel $\mathrm{A}^{3}$, Yogol $\mathrm{S}^{3}$, Poudel $\mathrm{A}^{3}$, Kunwor $\mathrm{K}^{3}$, Byanju $\mathrm{S}^{3}$
}

\author{
${ }^{1}$ Department of Internal medicine \\ ${ }^{2}$ Department of General Surgery \\ ${ }^{3}$ Department of Nursing \\ Dhulikhel Hospital, Kathmandu University Hospital \\ Dhulikhel, Kavre, Nepal
}

Corresponding Author

Ram B. Gurung

Department of Internal Medicine and Endoscopy Unit

Dhulikhel Hospital, Kathmandu University Hospital

Dhulikhel, Kavre, Nepal

Email: rambgurung7@gmail.com

\section{Citation}

Gurung RB, Purbe B, Malla B, Dhungel A,Yogol S, Poudel A, et al. Safety Profile and Patient Satisfaction of the Routine use of Propofol in Gastrointestinal Endoscopy. Kathmandu Univ Med J 2014;46(2):101-5.

\begin{abstract}
Backgroud

Routine use of sedation in upper gastrointestinal endoscopy is uncommon in Nepal. There is no study on use of propofol sedation in routine endoscopy examination in Nepal. This study was conducted in order to assess the patient satisfaction and safety profile in patient undergoing routine upper $\mathrm{Gl}$ endoscopic examination on outpatients.
\end{abstract}

\section{Objective}

To study safety profile and patient satisfaction of use of propofol in patients undergoing upper GI endoscopy.

\section{Method}

A prospective, observational study was conducted in the endoscopy unit of Dhulikhel hospital, Kathmandu University Hospital from July 2011 to 2012 July. Patients who were referred to upper GI endoscopy were offered to sedation under propofol. Informed consent was taken after explaining side effects, advantages and risk-benefit to the clients. The propofol was administered by the endoscopy nurse under guidance and supervision of the endoscopy performing physician.

Data were collected and analyzed using SPSS version 16.0 with 0.05 level of significance.

\section{Result}

Total of 203 patients included in the study. Among 203 patients, $21.2 \%$ were males and $78.8 \%$ were females; $83.7 \%$ were of less than of 60 years age and $16.3 \%$ above 60 years of age. The mean total dose of propofol required was $136.08 \pm 48.82 \mathrm{mg}$. Total of $29.1 \%$ of cases required $\mathrm{O}_{2}$ administration during the procedure time due to transient drop in $\mathrm{O}_{2}$ saturation. Total of $4.4 \%$ of cases required fluid administration due to transient fall in blood pressure. Total of $68.0 \%$ of cases were completely sedated; $28.6 \%$ had minor restless and $3.4 \%$ showed agitation during induction period of propofol sedation. Total of $99.5 \%$ of patients reported pleasant experience while 0.5\% reported unpleasant. Among 203 respondents, 98.5\% responded they would prefer to do the procedure under propofol sedation in the future; $1.5 \%$ responded they did not want sedations in the future.

\section{Conclusion}

Upper GI endoscopy can safely be performed under propofol sedation administered by registered trained nurse under the supervision of endoscopist.

\section{KEY WORD}

Endoscopy, patient safety, patient satisfaction, propofol sedation 


\section{INTRODUCTION}

The use of intravenous sedation in routine gastrointestinal endoscopy in Nepal is uncommon. The upper Gl endoscopy is commonly performed under pharyngeal Xylocain spray or gargle. As a sedative, the midazolam and the opiods are probably the agents employed by many endoscopists in Nepal. Although, the diagnostic upper GI endoscopy can be performed in most of the patients without intravenous sedation, the patient discomfort and un-cooperation is frequently encountered during the procedure resulting in compromisation with the quality of assessment and risk of incomplete examination. On the other hand, the use of benzodiazepam and opiods though effective and safe, has potential to cause longer post-procedure sedation and psychomotor in-coordination rendering the patients especially coming from far-off places or patients on automobile difficult or unsafe to return their home.

Propofol, (or 2-6 diisopropylphenol) is an ultrashort acting sedative hypnotic agent that has received increased attention for use during endoscopy. ${ }^{1-7}$ Propofol has a shorter time to recovery and, hence, earlier discharge from the endoscopy unit. Patients who receive propofol (half-life $2 \mathrm{~min}$ to $4 \mathrm{~min}$ ) as a single agent recover normal neurological and social functioning significantly quicker than benzodiazepines (half-life $30 \mathrm{~min}$ ) and/or narcotics (half-life $3 \mathrm{~h}$ to $4 \mathrm{~h}$ ). Therefore, a quicker onset of action and less patient discomfort; both of which benefit the endoscopist and the patient . 8-10 $^{-10}$

Several studies have addressed the safe and effective use of propofol during gastrointestinal endoscopy, by either physicians or trained nurses. In 2005 the cumulative reported experience with non-anesthesiologistsadministered propofol during gastrointestinal endoscopic procedures was more than 80000 patients. ${ }^{11-14}$ However, there are no studies on use of propofol in routine upper $\mathrm{GI}$ endoscopy practice in Nepal.

This study was conducted in order to assess the patient satisfaction and safety profile in patient undergoing routine endoscopic examination on outpatients

\section{METHODS}

A prospective, observational study was conducted in the endoscopy unit of Dhulikhel hospital, Kathmandu University hospital from July 2011 to 2012 July. Patients who were referred to upper GI endoscopy were offered to sedation under propofol. Informed consent was taken after explaining side effects, advantages and risk-benefit to the clients. The propofol was administered by the endoscopy nurse under the guidance and supervision of the endoscopy performing physician.

All the patients who gave written consent for use of propofol were enrolled. The exclusion criteria were: 1) patient with underlying cardio-respiratory diseases;
2) Unstable vital signs; 3) emergency conditions; 4) patient without a companion; and 4) patient who was unwilling or reluctant to have sedation after explanation.

After a thorough examination by the physician, the propofol was administered by the registered nurse who was trained in IV propofol sedation, monitoring and securing the basic airway maneuvers. Two nurses were employed: one for propofol administration and monitoring, and another for assisting the endoscopist. The continuous $\mathrm{O}_{2}$ saturation and pulse rate was monitored and recorded in the chart every two minute. Blood pressure was measured before administration of propofol and every five minute and at the end of procedure. Any change in $\mathrm{O}_{2}$ sat, pulse rate and blood pressure was informed to the physician and prompt appropriate actions were taken. The $\mathrm{O}_{2}$ supply, ambu bag and intubation set were ready at the patients side.

\section{Propofol administration:}

The propofol was administered as follow: an initial dose of 30-50 mg was followed by doses of 10-20 mg after 1 to 2 min later. Additional bolus doses was determined by the level of sedation and continuous clinical monitoring of vitals . The initial bolus dose was not exceeded more than $60 \mathrm{mg}$. The total dose of propofol, level of sedation, total duration of sedation and procedure time and recovery time were all recorded. Intra-procedural adverse events, interventions in the form of $\mathrm{O}_{2}$ administration, IV fluid administration, ambu-bagging/intubation were all documented. Interview with the patient on post-procedural effects and experience was obtained after full recovery. After the full recovery, all the patients were asked if they would prefer sedation should they have to repeat endoscopy in the future.

Data were collected and analyzed using SPSS version 16.0 with 0.05 level of significance.

\section{RESULTS}

Total of 203 patients who underwent upper GI endoscopy under propofol sedation administered by registered nurses were included in this study. Out of 203 patients, $83.7 \%$ were of less than of 60 years age. Among 203 patients, 21. $2 \%$ were males and $78.8 \%$ were females (Table 1 ).

Table 1. Demographic variables

$N=203$

\begin{tabular}{|c|c|c|}
\hline Variables & Number & Percentage \\
\hline \multicolumn{3}{|l|}{ Age } \\
\hline$</=16$ years & 10 & 4.9 \\
\hline $17-24$ & 43 & 21.3 \\
\hline $25-40$ & 55 & 27.1 \\
\hline $41-60$ & 62 & 30.5 \\
\hline 60 and above & 33 & 16.3 \\
\hline \multicolumn{3}{|l|}{ Sex } \\
\hline Male & 43 & 21.2 \\
\hline Female & 160 & 78.8 \\
\hline
\end{tabular}


Out of 203 cases, $172(84.7 \%)$ had onset of sedation within 2 minutes; 8 (3.9\%) within 3 min and 23 (11.4) had onset upto 4 minute. The mean total dose of propofol required was $136.08 \pm 48.82 \mathrm{mg}$. The full recovery from propofol sedation was $15.13 \pm 6.80 \mathrm{~min}$. Total of 138 (68.0\%) of cases were completely sedated; $58(28.6 \%)$ had minor restless, and $7(3.4 \%)$ had agitation during induction period of propofol sedation (Table 2).

Table 2. Dosage and effects of Propofol administration.

\begin{tabular}{|c|c|c|}
\hline Variables & Number & Percent \\
\hline \multicolumn{3}{|l|}{ Onset of sedation } \\
\hline $1 \mathrm{~min}$ & 92 & 45.3 \\
\hline $2 \mathrm{~min}$ & 80 & 39.4 \\
\hline $3 \min$ & 8 & 3.9 \\
\hline 4 and more & 23 & 11.4 \\
\hline \multicolumn{3}{|l|}{ Level of sedation } \\
\hline Complete & 138 & 68.0 \\
\hline Minor restless & 58 & 28.6 \\
\hline Violent & 7 & 3.4 \\
\hline Mean total dose of propofol & \multicolumn{2}{|c|}{$136.08 \pm 48.823 \mathrm{mg}$} \\
\hline Mean duration of procedure & \multicolumn{2}{|c|}{$6.91 \pm 5.66 \mathrm{~min}$} \\
\hline Recovered fully from sedation & \multicolumn{2}{|c|}{$15.13 \pm 6.80 \mathrm{~min}$} \\
\hline
\end{tabular}

The mean systolic blood pressure fall was $4.81 \mathrm{~mm} \mathrm{Hg}$; the mean pulse rate during the propofol administration was 87 $.71 \pm 13.8$ and the mean $\mathrm{O}_{2}$ saturation during the procedure was $94.89 \pm 2.81$ (Table 3).

Table 3. Change in vital signs during Propofol administration.

\begin{tabular}{|ccc|}
\hline Variables & $\begin{array}{c}\text { Before procedure } \\
\text { (mean } \pm \text { SD) }\end{array}$ & $\begin{array}{c}\text { During Procedure } \\
\text { (mean } \pm \text { SD) }\end{array}$ \\
\hline Systolic blood pressure & $114.29 \pm 17.201$ & $109.48 \pm 14.771$ \\
\hline Pulse rate - & $83.81 \pm 13.95$ & $87.71 \pm 13.822$ \\
\hline $\mathrm{SpO}_{2}$ & $96.75 \pm 2.315$ & $94.89 \pm 2.810$ \\
\hline
\end{tabular}

In one $(0.5 \%)$ patient the $\mathrm{O}_{2}$ saturation dropped below $85 \%$; the $\mathrm{O}_{2}$ saturation fall was between 86 to $89 \%$ in 8 (3.9\%); 90 to $93 \%$ in 32 (15.8\%). In 162 (79.8\%), there was no significant fall in $\mathrm{O}_{2}$ saturation during propofol administration ( Table 4).

Table 4. $\mathrm{SPO}_{2}$ changes during procedure

$\mathrm{N}=203$

\begin{tabular}{|ccc|}
\hline Variables & Number & Percent \\
\hline Category of $\mathrm{SPO}_{2}$ changes & & \\
\hline$<85 \%$ & 1 & 0.5 \\
\hline $85-90 \%$ & 8 & 3.9 \\
\hline $90-93 \%$ & 32 & 15.8 \\
\hline$>93 \%$ & 162 & 79.8 \\
\hline
\end{tabular}

Total of 59(29.1\%) cases required $\mathrm{O}_{2}$ administration during the procedure due to transient drop in $\mathrm{O}_{2}$ saturation; 9 (4.4\%) cases required intravenous fluid for the transient fall in systolic blood pressure (Table 5).
Table 5. Respiratory/Circulatory support required during procedure

$\mathrm{N}=203$

\begin{tabular}{lcc|}
\multicolumn{1}{c}{ Variables } & Number & Percent \\
\hline Respiratory support & 59 & \\
Required & 144 & 29.1 \\
\hline Not required & 59.9 \\
Oxygen therapy $(\mathrm{n}=59)$ & \\
\hline Yes & & 29.1 \\
Circulatory support & 9 & \\
\hline Required & 194 & 4.4 \\
Not required & & 95.6 \\
\hline
\end{tabular}

Post-procedure patient evaluation revealed: 202 (99.5\%) reported pleasant experience whereas only one $(0.5 \%)$ reported unpleasant; 200 (98.5\%) of patients responded that they would prefer propofol sedation again if had to undergo endoscopy in the future; only $3(1.5 \%)$ did not want propofol if needed repeat endoscopy examination in the future (Table 6).

Table 6. Patient satisfaction

$\mathrm{N}=203$

\begin{tabular}{|lcc|}
\hline \multicolumn{1}{|c}{ Variables } & Number & Percent \\
$\begin{array}{l}\text { Prefer propofol sedation if } \\
\text { repeat in the future }\end{array}$ & \\
\hline Yes & 200 & 98.5 \\
\hline No & 3 & 1.5 \\
\hline $\begin{array}{l}\text { Experience of propofol } \\
\text { sedation }\end{array}$ & & \\
\hline Pleasant & 202 & 99.5 \\
\hline Unpleasant & 1 & 0.5 \\
\hline
\end{tabular}

\section{DISCUSSION}

Although there are several studies on propofol administration in the west our study on nurse administered propofol sedation for routine upper GI endoscopy was first in Nepal. ${ }^{15-17}$

This study which included 203 patients comprised majority of female sex $(78.8 \%)$; and $83.8 \%$ of patients were of age less than 60 years (Table 1). This higher number of younger age and female sex could be due to increased incidence of anxiety related to endoscopy examination resulting in increased willingness to undergo procedure under sedation.

The majority of patients $172(84.7 \%)$ achieved complete sedation within 1 to 2 minutes (Table 2) with $68 \%$ having complete sedation, while $28.6 \%$ had minor restlessness during intubation, and $3.4 \%$ showed agitation during induction. However, all the patients successfully completed examination and recalled no unpleasant experience which shows the amnestic property of this sedative agent . 
In our study, the significant fall in $\mathrm{O}_{2}$ sat $(<90 \%)$ was seen in 9 (4.4\%); however, the effect was transient (less than one minute) and managed with simple airway securing maneuver : chin lift /jaw thrust, and $\mathrm{O}_{2}$ administration. This finding was comparable and even lower than some of the studies. ${ }^{18-21}$ None of the patients required endotracheal intubation, bag-mask ventilation or help by anesthesiologist. In a similar study done in Denmark showed up to $4.4 \%$ of patients events of hypoxemia (<92\%) and $1.1 \%$ needed assisted ventilation and anesthesiologic assistance was requested 10 times. Two patients required endotracheal intubation in this study; however, no mortality was seen in this study.$^{22}$

There was no significant fall in systolic blood pressure in our study. Out of 203 patients, 9 (4.4\%) required IV fluid bolus administration for transient fall in systolic blood pressure. No patient required more than $500 \mathrm{ml}$ of normal saline and all patients were discharged after full recovery on the same day. In the study by Jensen JT et al, among the 1764 patients, 554 (31\%) demonstrated a change in systolic blood pressure by more than $20 \mathrm{mmHg}$. All the episodes were transient (less than $2 \mathrm{~min}$ ) and managed with saline and trendelenburg maneuver. The mean total dose of propofol required in our study was $136.08 \pm 48.82$ mg (Table 2); where as in the study by Jensen JT et al it was $347 \mathrm{mg}$ (median $300 \mathrm{mg}$, range $50-1940 \mathrm{mg}$ ). ${ }^{22}$ This dose difference could also be the reason for more adverse events in this study.
Based on the interview taken at the time of discharge, 98.5 $\%$ said they would prefer propofol sedation again if they had to repeat endoscopy in the future. This high rate of satisfaction is attributable to amnestic effect of propofol. In one randomized study comparing propofol with midazolam and fentanyl during upper GI endoscopy, the satisfaction rate was significantly higher in propofol group 22

Our study has some limitations. The sample size is small compared to most published studies abroad. We enrolled patients mostly younger age group without any cardiorespiratory comorbidities which may explain the lower rate of adverse cardio-respiratory adverse events. Our assessment of patient satisfaction was based on the interview taken on the same day after full recovery.

\section{CONCLUSION}

Upper GI endoscopy can safely be administered by registered trained nurse under the supervision of trained physician endoscopist. However, continuous and careful monitoring of $\mathrm{O}_{2}, \mathrm{BP}$ and pulse rate along with provision to administer oxygen and secured IV line is mandatory. Nevertheless, extra cost of medicines, and human resources, and potential need for skilled intervention in case of serious cardio-respiratory compromise should be given serious thought before indicating propofol sedation in Nepal.

\section{REFERENCES}

1. Bell GD. Premedication, preparation, and surveillance. Endoscopy 2000;32:92-100.

2. Koshy G, Nair S, Norkus EP, Hertan HI, Pitchumoni CS. Propofol versus midazolam and meperdine for conscious sedation in Gl endoscopy. Am J Gastroenterol 2000;95:1476-9.

3. Carlsson U, Grattidge P. Sedation for upper gastrointestinal endoscopy: a comparative study of propofol and midazolam. Endoscopy 1995;27:240-3.

4. Roseveare C, Seavell C, Patel P, Criswell J, Kimble J, Jones C, et al. Patient-controlled sedation and analgesia, using propofol and alfentanil, during colonoscopy: a prospective randomized controlled trial. Endoscopy 1998;30:768-73.

5. Reimann FM, Samson U, Derad I, Fuchs M, Schiefer B, Stange EF. Synergistic sedation with low-dose midazolam and propofol for colonoscopies. Endoscopy 2000;32:239-44.

6. Jung $M$, Hofmann C, Kiesslich R, Brakertz A. Improved sedation in diagnostic and therapeutic ERCP: propofol is an alternative to midazolam. Endoscopy 2000;32:233-8.

7. Wehrmann T, Kokabpick S, Lembcke B, Caspary WF, Seifert H. Efficacy and safety of intravenous propofol sedation during routine ERCP: a prospective, controlled study. Gastrointest Endosc 1999;49:677-83.

8. Ng JM, Kong CF, Nyam D. Patient-controlled sedation with propofol for colonoscopy. Gastrointest Endosc. 2001;54:8-13.

9. Sipe BW, Rex DK, Latinovich D, et al. Propofol versus midazolam/ meperidine for outpatient colonoscopy: Administration by nurses supervised by endoscopists. Gastrointest Endosc 2002;55:815-25.

10. Ulmer BJ, Hansen JJ, Overley CA, et al. Propofol versus midazolam/ fentanyl for outpatient colonoscopy: Administration by nurses supervised by endoscopists.Clin Gastroenterol Hepatol 2003;1:425-32.

11. Rex DK, Heuss LT, Walker JA, Qi R. Trained registered nurses/ endoscopy teams can administer propofol safely for endoscopy. Gastroenterology 2005; 129: 1384-1391

12. Yusoff IF, Raymond G, Sahai AV. Endoscopist administered propofol for upper-GI EUS is safe and effective: a prospective study in 500 patients. Gastrointest Endosc 2004; 60: 356-360

13. Rex DK, Overley C, Kinser K, Coates M, Lee A, Goodwine, BW, Strahl E, Lemler S, Sipe B, Rahmani E, Helper D. Safety of propofol administered by registered nurses with gastroenterologist supervision in 2000 endoscopic cases. Am J Gastroenterol 2002; 97: 1159-1163

14. Külling D, Rothenbühler $R$, Inauen W. Safety of nonanesthetist sedation with propofol for outpatient colonoscopy and esophagogastroduodenoscopy. Endoscopy 2003; 35: 679-682.

15. Walker JA, Mclntyre RD, Schleinitz PF, Jacobson KN, Haulk AA, Adesman P, Tolleson S, Parent R, Donnelly R, Rex DK. Nurseadministered propofol sedation without anesthesia specialists in 9152 endoscopic cases in an ambulatory surgery center. Am J Gastroenterol 2003 Aug;98(8):1744-50.

16. Meah N, Parikh PB. Efficacy and safety of nurse-administered propofol as an adjunctive agent of conscious sedation in private non-academic gastroenterology practice setting . Am J Gastrenterol 2004;99:S313.

17. Heuss LT, Schnieper P, Drewe J, Pflimlin E, Beglinger C. Risk stratification and safe administration of propofol by registered nurses supervised by the gastroenterologist: a prospective observational study of more than 2000 cases. Gastrointest Endosc 2003; 57: 664-71. 
18. Gregory A. Coté, Robert M. Hovis, Michael A. Ansstas, Lawrence Waldbaum, Riad R. Azar, Dayna S. Early, Steven A. Edmundowicz, Daniel K. Mullady, Sreenivasa S. Jonnalagadda . Incidence of Sedationrelated Complications with Propofol Use during Advanced Endoscopic Procedures. Clin Gastroenterol Hepatol 2010;8(2):137-42.

19. Wehrmann T, Riphaus A. Sedation with propofol for interventional endoscopic procedures: a risk factor analysis. Scand J Gastroenterol 2008;43:368-374.

20. Paspatis GA, Manolaraki MM, Vardas E, et al. Deep sedation for endoscopic retrograde cholangiopancreatography: intravenous propofol alone versus intravenous propofol with oral midazolam premedication. Endoscopy 2008;40:308-313.
21. Fatima H, DeWitt J, LeBlanc J, et al. Nurse-administered propofol sedation for upper endoscopic ultrasonography. 2008;103:16491656.

22. Jensen JT P, Vilmann2,3, T. Horsted1, P. Hornslet3, U. Bodtger4, A. Banning1, A. Hammering1et al. Nurse-administered propofol sedation for endoscopy. Endoscopy 2011; 43: 716-22

23. B. E. Levitzky1, R. Lopez2, J. A. Dumot1, J. J. Vargo1 Moderate sedation for elective upper endoscopy with balanced propofol versus fentanyl and midazolam alone: a randomized clinical trial. Endoscopy 2012; 44: 13-20 